\title{
Multi-criteria Selection and Thermo-economic Optimization of an Organic Rankine Cycle System for a Marine Application
}

\author{
M. Kalikatzarakis ${ }^{1}$ and C. A. Frangopoulos ${ }^{* 2}$ \\ National Technical University of Athens \\ School of Naval Architecture and Marine Engineering \\ Heroon Polytechniou 9, 15780 Zografou, Greece \\ 1miltos_k@live.com, 2 caf@naval.ntua.gr
}

Received 03 November 2014, Revised 04 April 2015, Accepted 06 April 2015

\begin{abstract}
The purpose of this work is to investigate the possibility of exploiting the low-temperature thermal energy released from marine propulsion engines by an Organic Rankine Cycle system (ORCs) and determine an optimal design of such a system for a particular engine as an example. At first, taking into consideration thermodynamic properties of several fluids and regulations applicable in the marine environment, proper organic Rankine fluids are selected for further consideration. Alternative system configurations with different fluids are assessed with a multi-criteria approach based on performance indexes. The system with the highest value of the Composite Performance Indicator is further studied. The optimal synthesis, design and operation are determined with maximization of the Net Present Value as the objective function. The optimization problem is solved with a combination of a Genetic Algorithm and a Sequential Quadratic Programming Algorithm. Furthermore, a sensitivity analysis is performed with respect to important parameters. It is interesting to note how the optimal synthesis (configuration) of the system changes with changing operation profile of the propulsion engine. The presentation closes with suggestions for further work.
\end{abstract}

Keywords: Marine propulsion; heat recovery; organic Rankine cycle.

\section{Introduction}

Fuel expenses are the most significant operation expenses of ships. Long term research and development led to impressive improvements in propulsion engine efficiency, but further improvements are marginal. On the contrary, step-wise improvements in fuel consumption can be achieved by exploitation of the thermal energy released from the engines and integration of the whole energy system of a ship. Exhaust gas boilers are commonplace in contemporary vessels, but there is still a non-negligible quantity of low-temperature thermal energy, which is usually rejected to the environment. Mechanical or electric power generation from waste heat can be achieved using thermodynamic power cycles (steam and organic Rankine cycle, Kalina cycle, Goswami cycle, etc.) or direct processes (thermoelectric, thermionic, and piezoelectric devices). Heat driven power cycles are advanced or already mature, whereas direct conversion techniques are still under development [1]. With respect to heat driven power cycles, organic Rankine cycles (ORCs) have been the most prevalent systems for recovery of low-temperature thermal energy released from internal combustion engines. Related research has demonstrated a potential fuel economy improvement of around $10 \%$ with modern organic Rankine fluids and current advancements in expander technology [214]. The purpose of this work is to investigate the possibility of using an ORC system which will exploit the low-temperature thermal energy coming from the cooling circuits of the main engine, and determine an optimal design of such a system for a particular propulsion engine as an example [15]. It is worth noting that the literature review revealed that many papers have been written on the analysis and optimization for heat recovery on the exhaust gases, but very few have been focusing on the cooling systems alone.

\section{Description of the Marine Propulsion System}

The propulsion system comprises a turbocharged Diesel engine (Fig. 1). The thermal energy of the exhaust gases is exploited by an exhaust gas boiler, but the low-temperature thermal energy coming from cooling of the charging air, the cylinders and the lubricating oil is only partially used for fresh water production by distillation of sea water. The remaining is to be exploited by an Organic Rankine Cycle.

The power output of the engine at the Maximum Continuous Rating (MCR) is $72240 \mathrm{~kW}$, while the operating profile is given in Table 1. The partial load performance with respect to the released thermal energy and temperature levels of the various fluids of the system in Fig. 1 is presented in Figs. 2-3.

\section{Selection of Organic Fluids}

More than 75 fluids have been proposed for ORCs [16]. Taking into consideration the temperature levels of the heat sources in the particular application and regulations stated in Revised MARPOL Annex VI [17] regarding marine applications of ozone depleting substances, the organic fluids presented in Tables 2 and 3 are selected as working fluids in the systems studied in this work. 


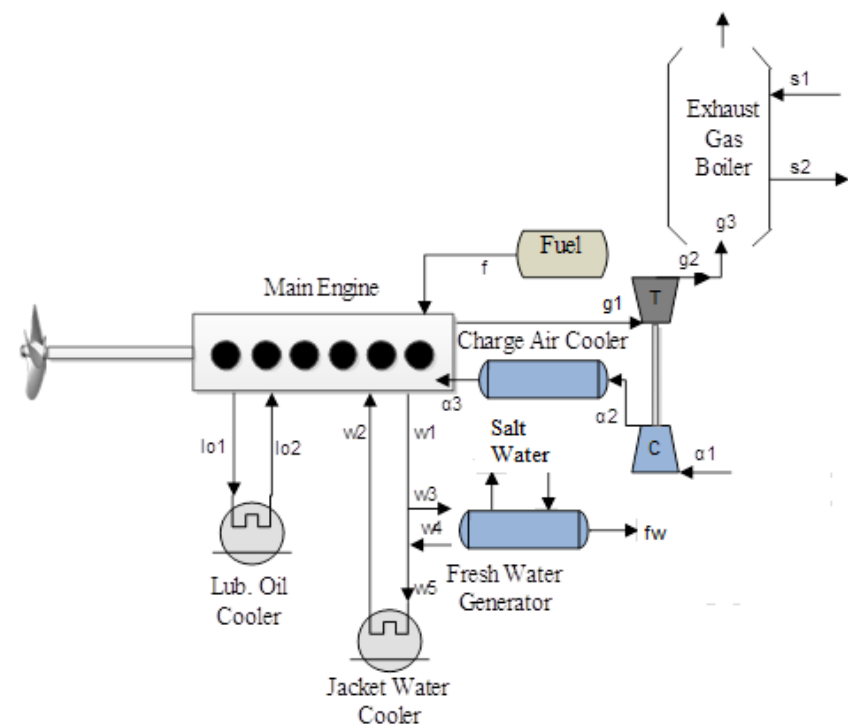

Figure 1. Simplified diagram of the marine propulsion system.

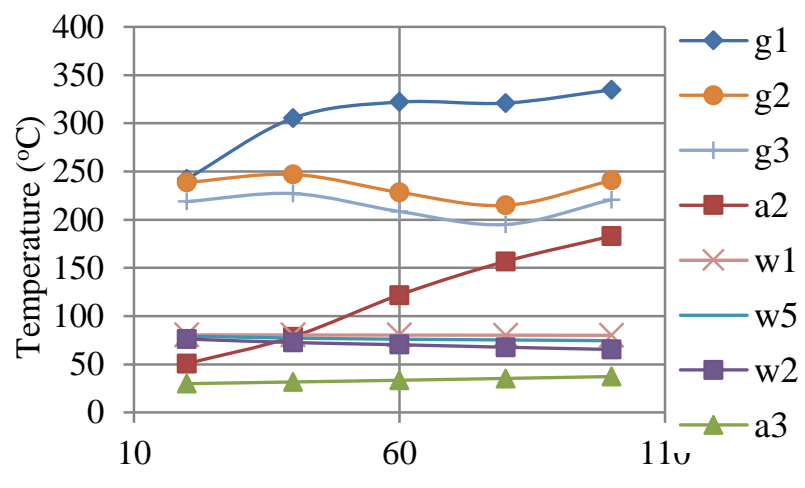

M/E Power Output (\% MCR)

Figure 2. Temperature levels of the various fluids.

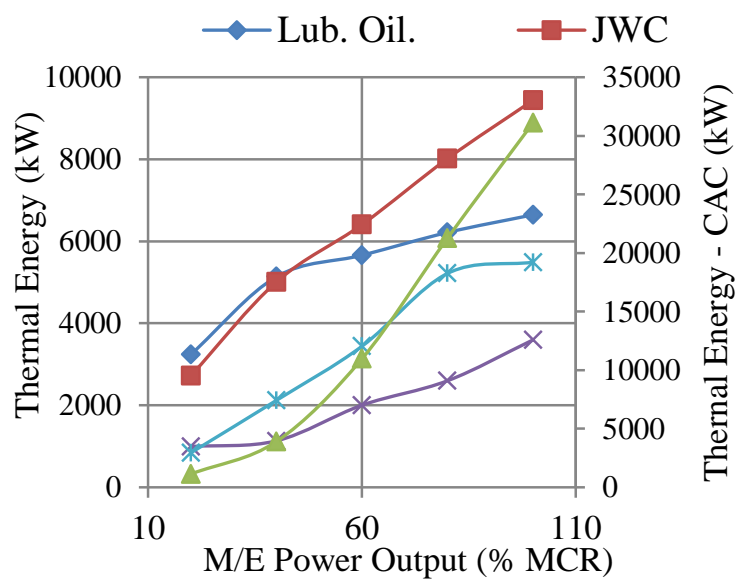

Fig. 3. Released thermal energy of the $M / E$.

Table 1. Operating Profile of the Diesel Engine.

\begin{tabular}{lrr}
\hline \multicolumn{2}{c}{ M/E Power Output, $\mathrm{kW}$} & Hours per year \\
\hline $20 \% \mathrm{MCR}$ & 14,448 & 757 \\
$40 \% \mathrm{MCR}$ & 28,896 & 1,562 \\
$60 \% \mathrm{MCR}$ & 43,344 & 2,007 \\
$80 \% \mathrm{MCR}$ & 57,792 & 327 \\
Other & & 347 \\
Total & & 5,000 \\
\hline
\end{tabular}

Table 2. Selected Simple Organic Fluids, with $O D P=0$.

\begin{tabular}{lccr}
\hline Fluid & $\mathrm{T}_{\text {crit. }}\left({ }^{\circ} \mathrm{C}\right)$ & p $_{\text {crit. }}($ bar $)$ & $\mathrm{GWP}_{100}$ \\
\hline R-134a & 101 & 40.5 & 1,300 \\
R-152a & 113 & 45.1 & 120 \\
R-227ea & 101 & 29.2 & 3,220 \\
R-236fa & 124 & 32.0 & 9,810 \\
R-236ea & 139 & 35.0 & 1,370 \\
R-245fa & 154 & 36.5 & 1,030 \\
R-245ca & 174 & 39.2 & 693 \\
R-C318 & 115 & 27.7 & 10,300 \\
R-600a & 134 & 36.2 & 3 \\
R-601a & 187 & 33.7 & 11 \\
Toluene & 318 & 41.2 & 2.7 \\
R-601 & 160 & 31.9 & 10 \\
\hline
\end{tabular}

Table 3. Selected Zeotropic Mixtures of Organic Fluids.

\begin{tabular}{lrc}
\hline Mixture components and fractions & $\mathrm{T}_{\text {crit. }}\left({ }^{\circ} \mathrm{C}\right)$ & p $_{\text {crit. }}$ (bar) \\
\hline $\mathrm{R}-245 \mathrm{ca} / \mathrm{R}-365 \mathrm{mfc}(0.5 / 0.5)$ & 180 & 37.6 \\
$\mathrm{R}-32$ / R-134a (0.3/0.7) & 94 & 45.8 \\
$\mathrm{R}-245 \mathrm{fa} / \mathrm{R}-152 \mathrm{a}(0.65 / 0.35)$ & 139 & 40.0 \\
$\mathrm{R}-245 \mathrm{fa} / \mathrm{R}-152 \mathrm{a}(0.45 / 0.55)$ & 131 & 41.8 \\
$\mathrm{R}-245 \mathrm{fa}$ / R-152a (0.9/0.1) & 149 & 37.6 \\
$\mathrm{R}-245 \mathrm{fa}$ / Isopentane $(0.5 / 0.5)$ & 170 & 41.7 \\
$\mathrm{R}-245 \mathrm{fa} / \mathrm{R}-365 \mathrm{mfc}(0.5 / 0.5)$ & 170 & 36.6 \\
$\mathrm{R}-245 \mathrm{fa}$ / Pentane $(0.5 / 0.5)$ & 175 & 40.4 \\
$\mathrm{R}-125$ / R-245fa $(0.939 / 0.061)$ & 71 & 36.5 \\
\hline
\end{tabular}

\section{Alternative ORC System Configurations and Their} Thermodynamic Performance

Three alternative configurations of the ORC system are examined: simple cycle, regenerative cycle and a combination of two ORC cycles, each one operating at different temperature levels. These systems recover thermal energy rejected by the lubricating oil cooling system, the jacket water cooling system, and the charge air cooler of the main engine. The flow diagrams of the integrated Diesel engine - ORC system are depicted in Figs. 4-6 (the exhaust gas boiler is not shown in Figs. 4-6 in order to save space).

By application of the pinch theory [18], the maximum possible power output of each system and fluid combination has been evaluated. The best combinations for each of the three systems are presented in Table 4, which gives the net power output $\dot{W}$, the specific power output $\dot{W} / \dot{m}$, the recovered waste heat flow rate $\dot{Q}_{i n}$, the heat recovery efficiency

$\eta_{Q}=\frac{Q_{\text {in }}}{Q_{a v}}$

where $Q_{a v}$ is the available heat, the Rankine cycle energy efficiency

$\eta_{R}=\frac{W}{Q_{\text {in }}}$

the total energy efficiency

$\eta_{t o t}=\frac{Q}{Q_{a v}}=\eta_{R} \eta_{Q}$

and the total exergy efficiency

$\zeta_{\text {tot }}=\frac{\varepsilon_{o u t}}{\varepsilon_{a v}}$

where $\varepsilon_{a v}$ is the exergy corresponding to $Q_{a v}$, and $\varepsilon_{\text {out }}$ is equal to $W$. 


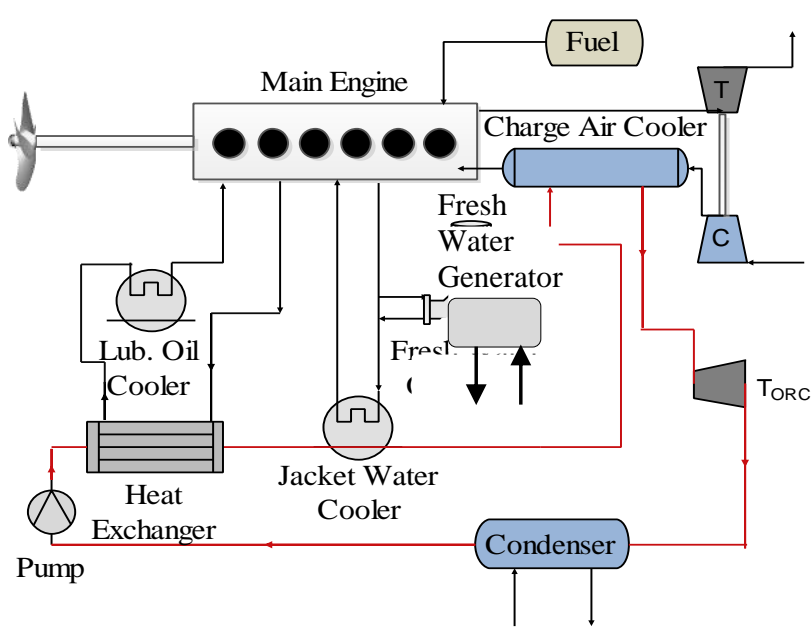

Figure 4. Integrated system with simple ORC.

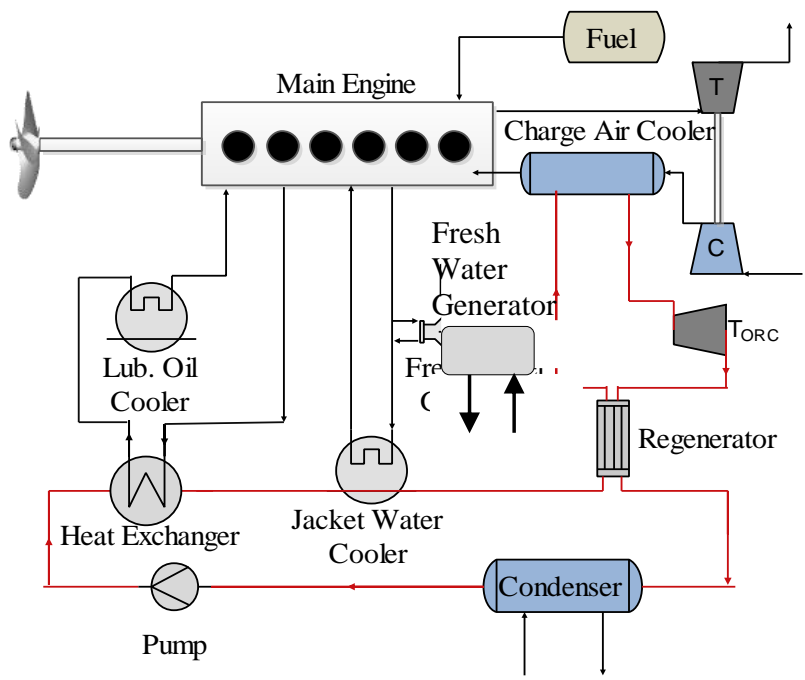

Figure 5. Integrated system with regenerative ORC.

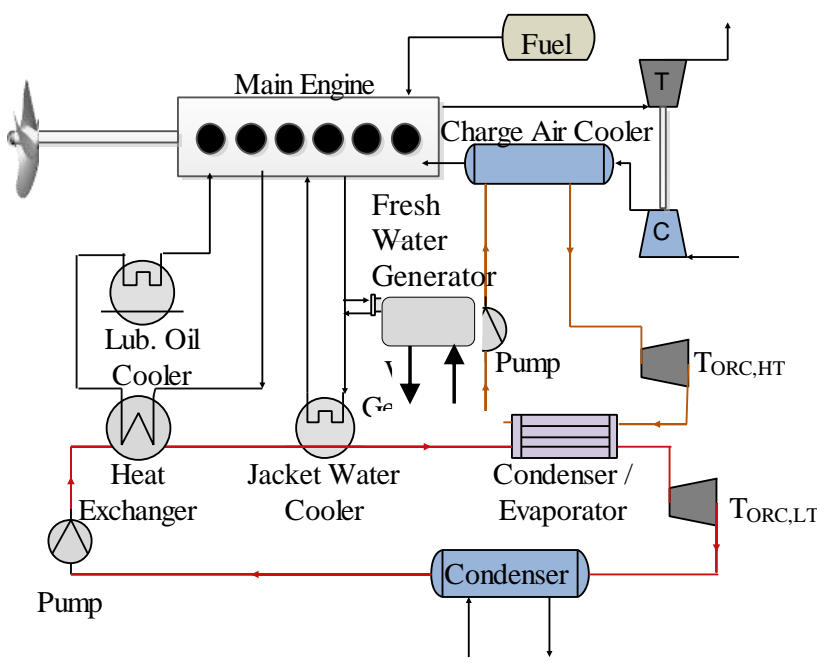

Figure 6. Integrated system with a combination of two ORCs.

In Table 4 , the values of $\dot{W}, \dot{W} / \dot{m}$ and $\dot{Q}_{\text {in }}$ are obtained for the nominal continuous rating of the engine $(85 \%$ of the maximum continuous rating). However, the values of the energy and exergy efficiencies are derived for a whole year of operation, taking the operating profile into consideration.
Table 4. Simple Organic Fluids and Zeotropic Mixtures of Fluids Giving the Maximum Power Output with Each Cycle.

\begin{tabular}{|c|c|c|c|c|c|c|c|}
\hline $\begin{array}{l}\text { Working } \\
\text { Fluid }\end{array}$ & $\begin{array}{l}\dot{\mathrm{W}} \\
\mathrm{kW}\end{array}$ & $\begin{array}{l}\dot{\mathrm{W}} / \dot{\mathrm{m}} \\
\mathrm{kJ} / \mathrm{kg}\end{array}$ & $\begin{array}{l}\dot{\mathrm{Q}}_{\text {in }} \\
\mathrm{kW}\end{array}$ & $\begin{array}{c}\eta_{Q} \\
\%\end{array}$ & $\begin{array}{l}\eta_{\mathrm{R}} \\
\%\end{array}$ & $\begin{array}{c}\eta_{\text {tot }} \\
\%\end{array}$ & $\begin{array}{c}\zeta_{\text {tot }} \\
\%\end{array}$ \\
\hline \multicolumn{8}{|c|}{ Simple ORC } \\
\hline $\begin{array}{l}\text { R-245fa } \\
\text { R-245ca / }\end{array}$ & 1,601 & 27.0 & 17,556 & 50.0 & 8.8 & 4.4 & 41 \\
\hline $\begin{array}{l}\text { R-365mfc } \\
(0.5 / 0.5)\end{array}$ & 1,177 & 28.2 & 13,261 & 44.2 & 8.6 & 3.8 & 32 \\
\hline \multicolumn{8}{|c|}{ Regenerative ORC } \\
\hline $\begin{array}{l}\mathrm{R}-245 \mathrm{fa} \\
\mathrm{R}-245 \mathrm{ca} /\end{array}$ & 1,541 & 25.8 & 15,810 & 48.9 & 9.2 & 4.6 & 43 \\
\hline $\begin{array}{l}\text { R-365mfc } \\
(0.5 / 0.5)\end{array}$ & 1,145 & 27.4 & 12,094 & 42.7 & 9.6 & 4.1 & 38 \\
\hline \multicolumn{8}{|c|}{ Combination of two ORCs } \\
\hline $\begin{array}{l}\text { R-245fa } \\
\& \text { R-413a } \\
\text { R-245ca / }\end{array}$ & 2,015 & 15.9 & 29,643 & 85.3 & 6.8 & 5.8 & 54 \\
\hline $\begin{array}{l}\text { R-365mfc } \\
(0.5 / 0.5) \\
\& \text { R-413a }\end{array}$ & 1,627 & 14.9 & 22,616 & 69.4 & 7.2 & 5.0 & 46 \\
\hline
\end{tabular}

A note on Figs. 4-6: The extra heat exchanger, which appears in Figs. 4-6 linked to the lubricating oil cooler of the main engine, indicates that complete cooling of the lubricating oil to the appropriate temperatures is not possible by the ORC systems, due to the fact that both the temperature of the lubricating oil entering the main engine and the temperature of the working fluid at the exit of the condenser equal $46^{\circ} \mathrm{C}$. Taking also into account the small temperature rise of the working fluid within the pump and the pinch point of the heat exchanger, it is clear that the ORC system cannot cool completely the lubricating oil to the needed temperature.

\section{Multi-criteria Evaluation of the Systems}

Technical, economic and environmental criteria combined will be used here for evaluation of the alternative configurations of systems and organic fluids. The technical criteria have been determined in the preceding section. In the following, the economic and environmental criteria will first be presented, followed by the description of the method and the results of multi-criteria evaluation.

\subsection{Economic Criteria}

Four economic criteria will be used for the evaluation of the systems: the initial investment, $\mathrm{C}_{0}$, the net present value (NPV) as determined with Eq. (5), the dynamic payback period (DPB) determined as the solution of Eq. (6) with respect to $\mathrm{N}_{\text {min }}$, and the internal rate of return (IRR) determined as the solution of Eq. (7) with respect to IRR.

$N P V=-C_{0}+\sum_{t=1}^{N}\left\{\frac{C_{f}\left(1+f_{f}\right)^{t-1}-C_{o m}(1+f)^{t-1}}{(1+i)^{t}}\right\}$

$-C_{0}+\sum_{t=0}^{N_{\min }=D P B}\left\{\frac{C_{f}\left(1+f_{f}\right)^{t-1}-C_{o m}(1+f)^{t-1}}{(1+i)^{t}}\right\} \geq 0$

$-C_{0}+\sum_{t=0}^{N}\left\{\frac{C_{f}\left(1+f_{f}\right)^{t-1}-C_{o m}(1+f)^{t-1}}{(1+I R R)^{t}}\right\}=0$

In order to obtain the total investment cost, a cost correlation has been used for each component of the system 
based on information found in the literature [2], [8], [19], [20]. The correlations are given in Table 5, while the values of the various economic parameters involved are given in Table 6.

Table 5. Component Costs.

\begin{tabular}{ll}
\hline Component & Cost $(€)$ \\
\hline Scroll expander & $1250.125+945 \dot{\mathrm{V}}_{\text {in, }}$ \\
Screw expander & $63.962+14.506 \dot{\mathrm{W}}_{\mathrm{T}}+63.962 \dot{\mathrm{W}}_{\mathrm{T}}^{2}$ \\
Heat exchangers & $1,500+2,185 \mathrm{~A}_{\mathrm{HEx}}$ \\
Pump & $3,340\left(\frac{\dot{\mathrm{W}}_{\mathrm{p}}}{300}\right)^{0.25}$ \\
& $\left(3.35+0.78 \mathrm{~d}_{\text {pipe }}\right) \mathrm{L}_{\text {pipe }}$ \\
Piping & $500 \dot{\mathrm{m}}$ \\
Working fluid & 1,000 \\
Misc. hardware & 1,000, Simple ORC \\
Control System & 1,300, Regenerative ORC \\
& 1,700, Combination of two ORCs \\
& $30 \%$ of the total component cost \\
\hline
\end{tabular}

Table 6. Values of Economic Parameters.

\begin{tabular}{ll}
\hline Parameter & Value \\
\hline $\mathrm{c}_{\mathrm{f}}$ & $0.5 € / \mathrm{kg}$ \\
$\mathrm{LHV}$ & $40,100 \mathrm{~kJ} / \mathrm{kg}$ \\
$\mathrm{SFOC}$ & $178 \mathrm{~g} / \mathrm{kWh}$ \\
$\mathrm{f}$ & $3 \%$ \\
$\mathrm{f}_{\mathrm{f}}$ & $4 \%$ \\
$\mathrm{i}$ & $10 \%$ \\
$\mathrm{~N}$ & 20 years \\
$\mathrm{c}_{\mathrm{om}}$ & $0.01 € / \mathrm{kWh}[21]$ \\
\hline
\end{tabular}

Table 7. Results of Economic Evaluation.

\begin{tabular}{|c|c|c|c|c|}
\hline $\begin{array}{l}\text { Working } \\
\text { Fluid }\end{array}$ & NPV $(€)$ & DPB (yrs) & $\operatorname{IRR}(\%)$ & $\mathrm{C}_{0}(€)$ \\
\hline \multicolumn{5}{|c|}{ Simple ORC } \\
\hline $\begin{array}{l}\mathrm{R}-245 \mathrm{fa} \\
\mathrm{R}-245 \mathrm{ca}\end{array}$ & 323,351 & 9 & 13.42 & $1,995,764$ \\
\hline $\begin{array}{l}\text { R-365mfc } \\
(0.5 / 0.5)\end{array}$ & 6,857 & 9.3 & 12.75 & $1,776,304$ \\
\hline \multicolumn{5}{|c|}{ Regenerative ORC } \\
\hline $\begin{array}{l}\mathrm{R}-245 \mathrm{fa} \\
\mathrm{R}-245 \mathrm{ca} /\end{array}$ & 14,812 & 10.2 & 11.32 & $2,277,625$ \\
\hline $\begin{array}{l}\text { R-365mfc } \\
(0.5 / 0.5)\end{array}$ & 18,276 & 10.9 & 9.95 & $1,987,759$ \\
\hline \multicolumn{5}{|c|}{ Combination of two ORCs } \\
\hline $\begin{array}{l}\text { R-245fa } \\
\& \text { R-413a } \\
\text { R-245ca / }\end{array}$ & 526,250 & 8.7 & 14.02 & $3,366,245$ \\
\hline $\begin{array}{l}\text { R-365mfc } \\
(0.5 / 0.5) \\
\& \text { R-413a }\end{array}$ & 6,519 & 10.2 & 10.98 & $2,564,935$ \\
\hline
\end{tabular}

The results of the economic evaluation are presented in Table 7. It can be seen that, from a purely economic standpoint, the optimal system to be installed is a combination of two ORCs with R-245fa and R-413a as working fluids for the HT and LT circuit, respectively, because it presents the highest net present value and internal rate of return among all the system studied and, of course, the lowest dynamic payback period. This occurs primarily due to the high energy output of this particular system, as can be seen in Table 4, which, in turn, allows higher fuel savings, with respect to the other configurations.

\subsection{Environmental Criteria}

The adoption of an ORC system as a means of electricity production, allows for saving significant amounts of fuel with simultaneous reduction in atmospheric emissions of pollutants. Thus, the evaluation of performance from the environmental standpoint will be based on the quantities of $\mathrm{CO}_{2}, \mathrm{NO}_{\mathrm{x}}$ and $\mathrm{SO}_{\mathrm{x}}$ non emitted to the environment by the Diesel generator sets of the ship, thanks to the operation of the Rankine cycle system.

In order to evaluate the quantity of $\mathrm{CO}_{2}$ avoided, a specific average amount of $\mathrm{CO}_{2}$ emitted by the Diesel generator sets, equal to $230 \mathrm{~g} / \mathrm{kWh}$ has been considered. By applying this value to the electric energy produced by the ORC and taking into account the annual hours of operation of the propulsion system (Table 1), the total amount of $\mathrm{CO}_{2}$ non emitted into the atmosphere can be obtained. $\mathrm{NO}_{\mathrm{x}}$ and $\mathrm{SO}_{\mathrm{x}}$ amounts non emitted can be calculated in the same way, assuming an average emission of $1.8 \mathrm{~g} / \mathrm{kWh}$ and $7.12 \mathrm{~g} / \mathrm{kWh}$, respectively. The results of the environmental performance for each system are presented in Table 8 .

Table 8. Results of Environmental Performance (quantities of pollutants non-emitted thanks to the operation of the ORC system).

\begin{tabular}{|c|c|c|c|}
\hline $\begin{array}{l}\text { Working } \\
\text { Fluid }\end{array}$ & $\mathrm{CO}_{2}$ (tons) & $\mathrm{NO}_{\mathrm{x}}$ (tons) & $\mathrm{SO}_{2}$ (tons) \\
\hline \multicolumn{4}{|c|}{ Simple ORC } \\
\hline $\mathrm{R}-245 \mathrm{fa}$ & 844.5 & 6.61 & 13.07 \\
\hline R-245ca / & & & \\
\hline $\mathrm{R}-365 \mathrm{mfc}$ & 702 & 5.49 & 10.86 \\
\hline \multicolumn{4}{|c|}{ Regenerative ORC } \\
\hline $\mathrm{R}-245 \mathrm{fa}$ & 833.87 & 6.52 & 12.90 \\
\hline $\mathrm{R}-245 \mathrm{ca} /$ & & & \\
\hline $\mathrm{R}-365 \mathrm{mfc}$ & 627.6 & 4.91 & 9.71 \\
\hline \multicolumn{4}{|c|}{ Combination of two ORCs } \\
\hline $\begin{array}{l}\text { R-245fa } \\
\& \text { R-413a }\end{array}$ & $1,052.42$ & 8.64 & 17.09 \\
\hline $\begin{array}{l}\text { R-245ca / } \\
\text { R-365mfc } \\
(0.5 / 0.5) \\
\& \text { R-413a }\end{array}$ & 892.05 & 6.98 & 13.80 \\
\hline
\end{tabular}

\subsection{Comments on the Thermodynamic and Economic Performance of the Systems}

Judging the systems clearly from a thermodynamic standpoint, it can be concluded from Table 4 that the best option is a combination of two ORCs with R-245fa and R413a as working fluids for the HT and LT cycle, respectively. By a closer examination of the thermodynamic data, it can be observed that this particular system seems to be the most suitable primarily because of its very high heat recovery efficiency, $\eta_{\mathrm{Q}}$ (it is noted that it is $22.91 \%$ higher than the second-high heat recovery efficiency in Table 4). This difference has a direct impact on the total efficiency, thus overshadowing the fact that the same system presents the absolute lowest Rankine cycle efficiency, when compared to the other systems in Table 4.

Moreover, judging purely from the economic point of view, the same system presents the highest net present value and the lowest dynamic payback period, but with significantly higher capital investment cost than the other systems, which can be a deterring factor for prospective investors (ship-owners). 
Taking into consideration all the aforementioned, it can be seen that there is no one perfect solution, which can satisfy all the criteria set. Thus, a multi-criteria evaluation of these systems is imperative, as will be presented in Sections 5.4 and 5.5 .

\subsection{Description of the Multi-criteria Evaluation Method}

The ASPID method will be used for the evaluation of the systems, according to the following procedure, as described in [22] and applied in [23]. Proper indicators are defined and normalized; next they are grouped in order to form sub-indices, which are then used to determine the composite performance index for each system, on which the choice of ORC system and working fluid (or fluids) will be based.

The indicator $i$ of the group $j$ will be symbolized with $I_{i j}$. The groups involve technical $(j=1)$, economic $(j=2)$ and environmental $(j=3)$ criteria of evaluation. Each indicator is normalized as follows:

For an indicator of the type "more is better":

$\bar{I}_{i j}=\left\{\begin{aligned} 0, & \text { if } I_{i j} \leq a_{i j} \\ \frac{I_{i j}-a_{i j}}{b_{i j}-a_{i j},} & \text { if } a_{i j}<I_{i j}<b_{i j} \\ 1, & \text { if } I_{i j} \geq b_{i j}\end{aligned}\right.$

For an indicator of the type "less is better":

$\bar{I}_{i j}=\left\{\begin{aligned} 1, & \text { if } I_{i j} \leq a_{i j} \\ \frac{b_{i j}-I_{i j}}{b_{i j}-a_{i j}}, & \text { if } a_{i j}<I_{i j}<b_{i j} \\ 0, & \text { if } I_{i j} \geq b_{i j}\end{aligned}\right.$

In Eqs. (4) and (5), $a_{i j}$ is the lower threshold or limit of $I_{i j}$ and $b_{i j}$ is the upper threshold or limit of $I_{i j}$. For the efficiencies, a lower threshold of zero (0) has been chosen. The upper threshold for the exergetic efficiency is set equal to one (1).

The upper threshold of the energetic efficiency has been calculated as follows: There are three heat sources (charge air, cooling water and lubricating oil), each with its own maximum temperature. A Carnot cycle is considered to be operating with each of the available heat sources, and the related Carnot efficiency is calculated. The upper threshold is then calculated as a weighted average of the three individual Carnot efficiencies, taking into consideration the quantity of the heat available for each cycle.

Regarding all the other indicators, their lower and upper thresholds are set equal to the lowest and highest values of all the different configurations, as obtained by the systems' indicators.

The sub-index for each group of indicators is determined by the equation:

$\bar{I}_{s j}=\sum_{i} w_{i j} \bar{I}_{i j}$

where $w_{i j}$ is the relative weight of indicator $i$ in group $j$ of indicators $\left(\sum_{\mathrm{i}} w_{i j}=1, w_{i j} \geq 0\right)$. In this work the same relative weight has been considered for all the indicators in a group.

Finally, the composite performance index for each system is given by the equation
$I_{c s}=\sum_{i} w_{j} \bar{I}_{s j}$

where $w_{j}$ is the relative weight of group $j$ of indicators $\left(\sum_{\mathrm{j}} w_{j}=1, w_{j} \geq 0\right)$. Again, the same relative weight has been considered for all the groups.

\subsection{Results of Multi-criteria Evaluation of the Systems}

The results of the multi-criteria evaluation of the ORC systems are presented in Tables $9-12$. The various indicators along with their lower and upper thresholds are presented in Table 9. The normalized values of the indicators for each system are given in Tables $10-11$, while the values of the sub-indices and the composite performance index are given in Table 12 .

Table 9. Values of the Indicators and Their Lower and Upper Thresholds.

\begin{tabular}{rllrr}
\hline Indicator & $\begin{array}{l}\text { Physical } \\
\text { symbol }\end{array}$ & Units & $\begin{array}{l}\text { Lower } \\
\text { threshold }\end{array}$ & $\begin{array}{l}\text { Upper } \\
\text { threshold }\end{array}$ \\
\hline $\mathrm{I}_{1,1}$ & $\dot{\mathrm{W}}$ & $\mathrm{kW}$ & 1,144 & 2,015 \\
$\mathrm{I}_{2,1}$ & $\dot{\mathrm{W}} / \dot{\mathrm{m}}$ & $\mathrm{kJ} / \mathrm{kg}$ & 14.9 & 28.2 \\
$\mathrm{I}_{3,1}$ & $\eta_{\text {tot }}$ & - & 0.032 & 0.058 \\
$\mathrm{I}_{4,1}$ & $\zeta_{\text {tot }}$ & - & 0 & 1 \\
$\mathrm{I}_{1,2}$ & $\mathrm{C} 0$ & $€$ & $1,776,304$ & $3,366,245$ \\
$\mathrm{I}_{2,2}$ & $\mathrm{DPB}$ & years & 8.7 & 10.2 \\
$\mathrm{I}_{3,2}$ & $\mathrm{NPV}$ & $€$ & 6,519 & 526,250 \\
$\mathrm{I}_{4,2}$ & $\mathrm{IRR}$ & $\%$ & 9.8 & 13.9 \\
$\mathrm{I}_{1,3}$ & $\mathrm{CO}_{2}$ & tons & 627.56 & $1,052.42$ \\
$\mathrm{I}_{2,3}$ & $\mathrm{NO}_{\mathrm{x}}$ & tons & 4.91 & 8.64 \\
$\mathrm{I}_{3,3}$ & $\mathrm{SO}_{2}$ & tons & 9.71 & 17.09 \\
\hline
\end{tabular}

Table 10. Normalized Values of the Indicators for the Simple and Regenerative ORC Systems.

\begin{tabular}{ccccc}
\hline & \multicolumn{2}{c}{ Simple ORC } & \multicolumn{2}{c}{ Regenerative ORC } \\
\cline { 2 - 5 } Indicator & R-245fa & $\begin{array}{c}\text { R-245ca/ } \\
\text { R-365mfc } \\
(0.5 / 0.5)\end{array}$ & R-245fa & $\begin{array}{c}\text { R-245ca / } \\
\text { R-365mfc } \\
(0.5 / 0.5)\end{array}$ \\
\hline $\mathrm{I}_{1,1}$ & 0,455 & 0,037 & 0,432 & 0,000 \\
$\mathrm{I}_{2,1}$ & 0,913 & 1,000 & 0,824 & 0,940 \\
$\mathrm{I}_{3,1}$ & 0,488 & 0,478 & 0,509 & 0,531 \\
$\mathrm{I}_{4,1}$ & 0,413 & 0,315 & 0,430 & 0,380 \\
$\mathrm{I}_{1,2}$ & 0,862 & 1,000 & 0,685 & 0,867 \\
$\mathrm{I}_{2,2}$ & 0,864 & 0,727 & 0,318 & 0,000 \\
$\mathrm{I}_{3,2}$ & 0,593 & 0,209 & 0,015 & 0,022 \\
$\mathrm{I}_{4,2}$ & 0,853 & 0,688 & 0,334 & 0,000 \\
$\mathrm{I}_{1,3}$ & 0,511 & 0,175 & 0,486 & 0,000 \\
$\mathrm{I}_{2,3}$ & 0,456 & 0,155 & 0,432 & 0,000 \\
$\mathrm{I}_{3,3}$ & 0,455 & 0,156 & 0,434 & 0,000 \\
\hline
\end{tabular}

As mentioned at the end of Section 5.3, no one of the systems presented in Table 4 is optimum with respect to all the optimization criteria. Therefore, a multi-criteria approach is applied and the system with the highest value of the composite performance index is selected.

Taking into consideration the values of the composite performance indexes for each system (Table 12), it is concluded that the optimal ORC system is a combination of two ORCs, using R-245fa as the working fluid for the HT cycle and R-413a for the LT cycle. From Table 11 it can be seen that this particular configuration presents the maximum values for economic and environmental criteria that have been specified and presented in the previous sections, and also the maximum power output, with respect to all the alternative configurations. However, the indicators for the energetic and exergetic efficiencies, the specific 
power output of the system and the initial investment are not particularly high.

Table 11. Normalized Values of the Indicators for the Combination of two ORC Systems.

\begin{tabular}{ccc}
\hline Indicator & $\begin{array}{c}\text { R-245fa \& } \\
\text { R413a }\end{array}$ & $\begin{array}{c}\text { R-245ca / R-365mfc (0.5/0.5) } \\
\text { \& R413a }\end{array}$ \\
\hline $\mathrm{I}_{1,1}$ & 1,000 & 0,555 \\
$\mathrm{I}_{2,1}$ & 0,075 & 0,000 \\
$\mathrm{I}_{3,1}$ & 0,377 & 0,400 \\
$\mathrm{I}_{4,1}$ & 0,540 & 0,460 \\
$\mathrm{I}_{1,2}$ & 0,000 & 0,504 \\
$\mathrm{I}_{2,2}$ & 1,000 & 0,318 \\
$\mathrm{I}_{3,2}$ & 1,000 & 0,000 \\
$\mathrm{I}_{4,2}$ & 1,000 & 0,253 \\
$\mathrm{I}_{1,3}$ & 1,000 & 0,622 \\
$\mathrm{I}_{2,3}$ & 1,000 & 0,555 \\
$\mathrm{I}_{3,3}$ & 1,000 & 0,554 \\
\hline
\end{tabular}

Table 12. Values of the Sub-indices and the Composite Performance Index.

\begin{tabular}{|c|c|c|c|c|}
\hline Working Fluid & $\mathrm{I}_{\mathrm{s}, 1}$ & $\mathrm{I}_{\mathrm{s}, 2}$ & $\mathrm{I}_{\mathrm{s}, 3}$ & $\mathrm{I}_{\mathrm{cs}}$ \\
\hline $\begin{array}{l}\mathrm{R}-245 \mathrm{fa} \\
\mathrm{R}-245 \mathrm{ca} / \\
\mathrm{R}-365 \mathrm{mfc}(0.5 / 0.5)\end{array}$ & $\begin{array}{l}\text { le OR } \\
0,57\end{array}$ & 0,79 & 0,47 & 0,61 \\
\hline $\begin{array}{l}\text { R-245fa } \\
\text { R-245ca / } \\
\text { R-365mfc }(0.5 / 0.5)\end{array}$ & $\begin{array}{r}\text { ative } \\
0,55\end{array}$ & $\begin{array}{l}\mathrm{RC} \\
0,34 \\
0,22 \\
\end{array}$ & $\begin{array}{l}0,45 \\
0,00\end{array}$ & 0,44 \\
\hline $\begin{array}{l}\text { R-245fa } \\
\text { \& R-413a } \\
\text { R-245ca / } \\
\text { R-365mfc }(0.5 / 0.5) \\
\text { \& R-413a }\end{array}$ & $n$ of to & ORC & 1,00 & 0,75 \\
\hline
\end{tabular}

\section{ORC System Optimization}

The system with the best composite performance index is optimized in the following with the net present value as objective function.

\subsection{Mathematical Statement of the Optimization Problem}

Two levels of optimization are performed simultaneously: design and operation optimization.

The first level (operation optimization) aims at maximizing the net savings (operation and maintenance costs subtracted from the fuel savings) that result from the operation of the ORC system, for each load of the main engine. The objective function is stated by the equation

$\max _{x_{k}} \varphi_{k}\left(x_{k}\right)=\left[\left(c_{f} S F O C-c_{o m}\right) \dot{W} H\right]_{k}$

where $k(=1,2,3,4)$ denotes each one of the loading conditions appearing in Table 1.

In Eq. (12), $H$ represents the annual hours of operation at the load $k$ of the main engine and $x_{k}$ represents the optimization variables regarding the first stage of optimization:

$x_{k}=\left(\dot{m}_{O R C, H T}, \dot{m}_{O R C, L T}, p_{\max O R C, H T}, p_{\max O R C, L T}\right)_{k}$

The second level (design optimization) aims at maximizing the net present value of the system: $\max _{\mathrm{x}, \mathrm{Z}} \mathrm{NPV}=-C_{0}+\sum_{t=1}^{N}\left\{\frac{C_{f}\left(1+f_{f}\right)^{t-1}-C_{o m}(1+f)^{t-1}}{(1+i)^{t}}\right\}$

In Eq. (14), $z$ represents the independent design optimization variables of the ORC system. In the present study, only the design characteristics of the plate heat exchangers are selected as independent design optimization variables:

$z_{j}=\left(N_{p}, t, L_{V}, L_{P}, L_{w}\right)_{\mathrm{j}}$

where $j(=1,2,3,4,5)$ an index for each of the ORC system's heat exchangers. In Eq. (15) $N_{p}$ is the number of plates of the heat exchanger, $t$ is the plate thickness, and the dimensions $L_{p}, L_{v}, L_{w}$ are defined in Fig 7.

It is worth noting that design characteristics of a heat exchanger (variables $z_{j}$ ) affect the overall heat transfer coefficient (and consequently the heat transfer area), as well as the pressure drop in the heat exchanger. Thus, the capital cost is affected (Table 5), as well as the operating cost through the power consumed by the pump. Furthermore, the pump power affects the net power output and consequently the maintenance cost (the parameter $c_{o m}$ in Table 5 is given per kWh of electric energy output) and, of course, the savings and finally the NPV.

The ORC system optimization contains $4 \times 4=16$ independent operation variables and $5 \times 5=25$ independent design variables, 41 independent optimization variables in total.

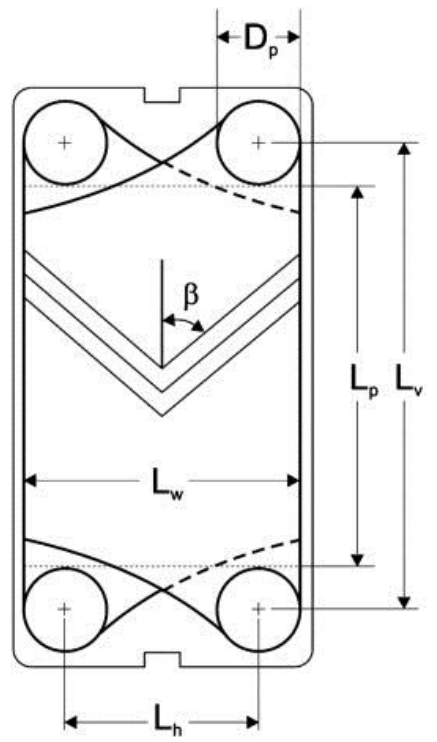

Figure 7. Plate main dimensions [24].

The optimization problem is solved using a hybrid scheme, the combination of a Genetic Algorithm (GA) and a Sequential Quadratic Programming (SQP) Algorithm. The optimization process starts by using the Genetic Algorithm, in order for the near optimal solution to be found, and the search is then continued by means of the SQP method. The combination of these two methods has been chosen because genetic algorithms, in case of polytropic objective functions, are able to locate nearly every local optimum, one of which will be the global optimum. However, it is sometimes possible that a genetic algorithm, due to its very nature, may not locate the global optimum precisely. This disadvantage (along with the problem of slow convergence) can be overtaken by combining these two algorithms. 


\subsection{Results of Optimization and Sensitivity Analysis}

Tables 13 and 14 give the optimum values of the independent variables. For the operation independent variables, only one set of values is given, because they present the same value in all four modes of operation given in Table 1.

The net present value of the system is $654,450 €$. The total investment cost of the optimized ORC system equals $1,748,629 €$, with a dynamic payback period of 6.3 years. As far as environmental remarks are concerned, 428.5 tons $\mathrm{CO}_{2}, 3.13$ tons $\mathrm{NO}_{\mathrm{x}}$, and 6.19 tons $\mathrm{SO}_{2}$ are non-emitted into the atmosphere thanks to the operation of the ORC system.

A sensitivity analysis has been performed with respect to the specific cost of Diesel oil used by the generators and the operating profile of the propulsion system's main engine, according to Table 15, along with its annual period of operation. The results are presented in Figs. 8-10.

Table 13. Optimum Values of the Operation Independent Variables.

\begin{tabular}{lllc}
\hline$\dot{\mathrm{m}}_{\mathrm{ORC}, \mathrm{LT}}$ & $\dot{\mathrm{m}}_{\mathrm{ORC}, \mathrm{HT}}$ & $\mathrm{p}_{\mathrm{ORC}, \mathrm{LT}}$ & $\mathrm{p}_{\mathrm{ORC}, \mathrm{HT}}$ \\
\hline $71 \mathrm{~kg} / \mathrm{sec}$ & $0 \mathrm{~kg} / \mathrm{sec}$ & $20 \mathrm{bar}$ & not defined \\
\hline
\end{tabular}

Table 14. Optimum Values of the Design Independent Variables.

\begin{tabular}{lrrrrr}
\hline & $N_{p}$ & $\begin{array}{c}t \\
(\mathrm{~mm})\end{array}$ & $\begin{array}{c}L_{V} \\
(\mathrm{~mm})\end{array}$ & $\begin{array}{c}L_{P} \\
(\mathrm{~mm})\end{array}$ & $\begin{array}{c}L_{W} \\
(\mathrm{~mm})\end{array}$ \\
\hline $\begin{array}{l}\text { Condenser } \\
\text { Evaporator / }\end{array}$ & 512 & 2.5 & 1,835 & $1,306.2$ & 610 \\
$\begin{array}{l}\text { Condenser } \\
\text { Lub. Oil heat } \\
\text { exchanger }\end{array}$ & - & - & - & - & - \\
$\begin{array}{l}\text { Jacket water } \\
\text { cooling heat } \\
\text { exchanger }\end{array}$ & 176 & 2.6 & 1,826 & 1388 & 480 \\
$\begin{array}{l}\text { Charge air cooler } \\
\text { heat exchanger }\end{array}$ & 264 & 2.6 & 1,826 & 1,388 & 480 \\
\hline
\end{tabular}

Table 15. Alternative Operating Profiles of the Propulsion Engine.

\begin{tabular}{crrr}
\hline $\begin{array}{c}\text { M/E Power Output, } \\
\mathrm{kW}\end{array}$ & $\begin{array}{c}\text { Operating } \\
\text { profile 1 }(\%)\end{array}$ & $\begin{array}{c}\text { Operating } \\
\text { profile 2 }(\%)\end{array}$ \\
\hline 25\% MCR & 18,060 & 16.47 & 1.50 \\
$50 \% \mathrm{MCR}$ & 36,120 & 32.75 & 6.99 \\
$75 \% \mathrm{MCR}$ & 54,180 & 41.76 & 4.99 \\
$85 \% \mathrm{MCR}$ & 61,404 & 7.77 & 84.99 \\
100\% MCR & 72,240 & 1.26 & 1.53 \\
Total & & 100 & 100 \\
\hline
\end{tabular}

\subsection{Comments on the Results of Optimization and Sensitivity Analysis}

Table 13 indicates zero mass flow rate of the high temperature cycle as the optimum value. This means that the combination of two ORCs, selected as the preferable cycle from the multi-criteria evaluation of the alternative ORC configurations, degenerates into a simple ORC with $\mathrm{R}-413 \mathrm{a}$ as the working fluid.

This occurs due to the relatively low loads of operation of the main engine throughout the year, as presented in Table 1. For operation of the main engine between $40 \%$ and $60 \%$ of the maximum continuous rating, the temperature at point $\mathrm{a}_{2}$ (Figs. 1 and 2) is reduced from $183^{\circ} \mathrm{C}$ at the nominal point to the range between $60-120^{\circ} \mathrm{C}$. Thus, it is preferable to install a simple ORC to the propulsion system, which will exploit the heat from all the available sources rather than installing an HT cycle which will recover waste heat only from the charge air, consequently increasing the total investment cost without much savings during operation. However, under favorable operating conditions, the installation of the HT cycle could be economically feasible, as described in the following.

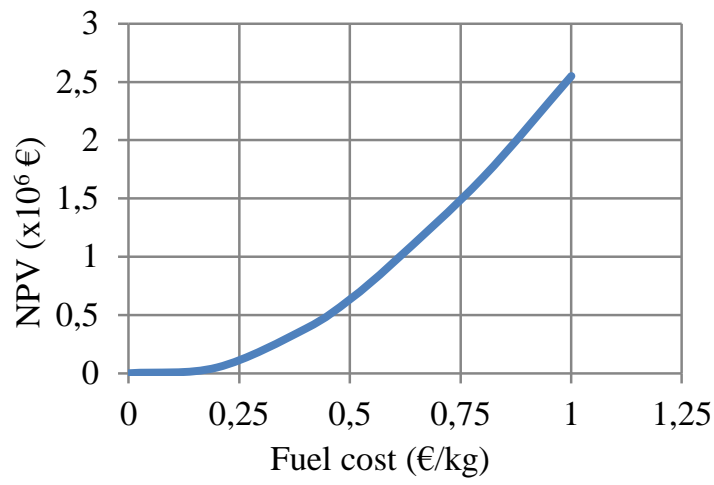

Figure 8. Effect of fuel cost on the optimum value of the objective function.

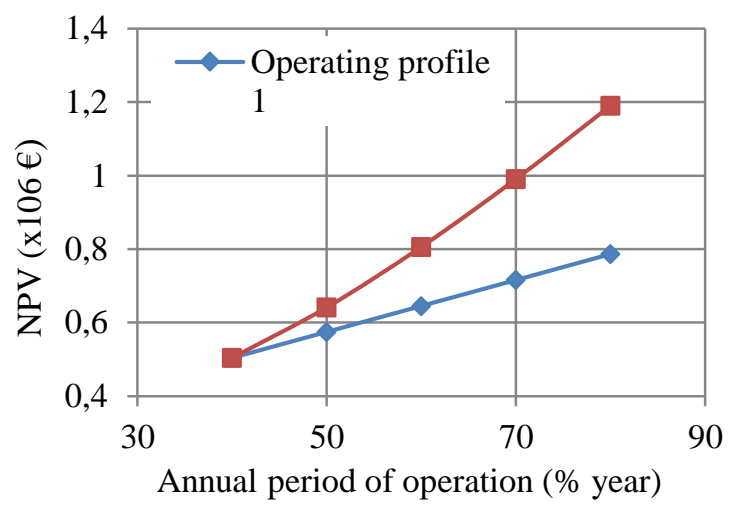

Figure 9. Effect of the annual period of operation (\% of the 8760 hours of a year) and the operating profile (Table 15) on the optimum value of the objective function.

The operating profile given in Table 1 is characterized by relatively low loads of the main engine (due to low speed of the vessel) and few hours of operation per year. In order to study the effect of the period of operation and operating profile on the optimal synthesis, design and operation of the ORC system, the optimization problem has been solved for several periods of operation from $40 \%$ to $80 \%$ of the year (3504 to 7008 hours per year) and two different operating profiles (load distributions) given in Table 15 for each period. In profile 1 , the engine operates at relatively low loads most of the time, while in profile 2 the engine operates at high loads most of the time.

The effect of the annual period of operation and of the operating profile on the NPV is shown in Fig. 9. With both profiles, the net present value of the investment increases significantly, as the period of operation rises. It is worth noting that the increase of the NPV of the operating profile 2 with the increase of the annual period of operation is much stronger than the increase of the NPV of the operating profile 1 . This occurs primarily because the higher temperatures (which stem from the operation of the main engine in relatively high loads) lead to higher temperatures of operation of the ORC, increasing the net power output of the system, thus the annual fuel savings. 


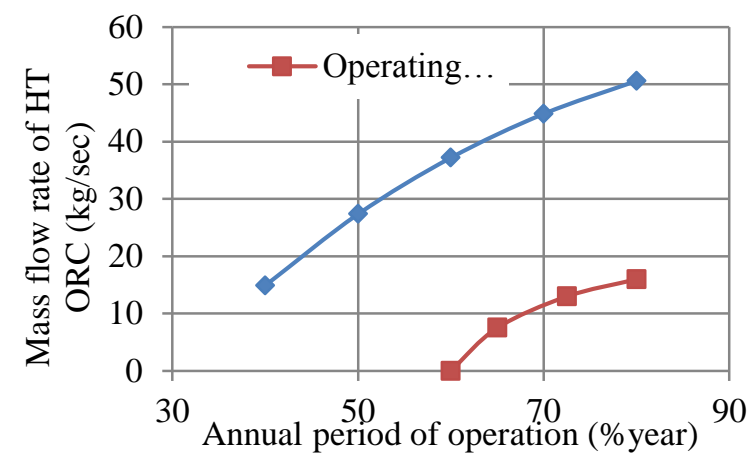

Figure 10. Effect of the annual period of operation and the operating profile on the mass flow rate of the hightemperature ORC.

As shown in Fig. 10, for the operating profile 1, the mass flow rate of the HT cycle is non-zero (thus a combination of two ORCs is preferred, as indicated by the multi-criteria evaluation), when the annual period of operation exceeds $60 \%$ of the year $(5,256 \mathrm{hrs})$. This occurs due to the proportional increase of the higher loads (> $80 \%$ MCR) of the main engine, and consecutively, the annual hours during which the inlet temperature of the charge air cooler is high enough to render the installation of the HT cycle an economically feasible solution. For the operating profile 2, a non-zero mass flow rate for the HT cycle has resulted for all periods of operation between $40 \%$ and $80 \%$ of the year, thus a combination of two ORCs is the optimum solution for recovering waste heat from the propulsion system when the main engine operates primarily at relatively high $(>80 \%$ MCR) loads. Thus, with the procedure applied here, based on the concept of superstructure, the optimal synthesis of the system is revealed in each case.

\section{Closure}

Organic Rankine cycles appear to be a feasible technology for large marine propulsion systems, from both the thermodynamic and the economic standpoint. In this work, three different ORC systems and 21 working fluids have been studied, in order to obtain the optimum solution for a particular propulsion system. A thermodynamic model was initially developed which, along with pinch analysis, allowed for a first selection of the working fluids. Then, the ASPID method was used for the multi-criteria evaluation of the systems, taking into account technical, economic and environmental aspects for each one. Finally, the dual-stage, hybrid scheme optimization of the best system, as indicated by the ASPID method, revealed the optimum synthesis and design characteristics of the ORC system to be installed.

In the present work, certain simplifying assumptions were made, which can be relaxed in future work. A few examples are the following.

(i) The pinch theory mentioned at the beginning of Section 4 has been applied at full load of the main engine and, consequently, the best combinations of system and working fluids have been determined for that condition. For a more accurate treatment, the operating profile given in Table 1 should be taken into consideration.

(ii) For the economic evaluation, the same equation was used for the cost of all the working fluids, as can be seen in Table 5, which in certain cases may have as a consequence non-accurate results. Thus, it would be

useful to supplement the evaluation procedure with more specific information regarding the cost of each working fluid separately.

(iii) The evaluation of the overall heat transfer coefficient (U) of a heat exchanger can be more accurate, if the heat exchanger is divided into $n$ sections and each section is considered as an individual heat exchanger in a procedure described in [25].

(iv) Off-design performance prediction of crucial components of the system would make the results more accurate.

\section{Acknowledgments}

The authors express their appreciation to Dr. N. Kakalis and Dr. G. Dimopoulos of Det Norske Veritas for their encouragement to investigate the particular subject and the useful information they provided.

\section{Nomenclature}

a

A

$b$

$c$

C

$$
\mathrm{d}
$$

$D P B$

$G W P$

$f$

$H$

$h p w$

$i$

I

$\bar{I}$

IRR

L

$L H V$

$\dot{m}$

MCR

$N_{p}$

$N P V$

$O D P$

$p$

$Q$

$\dot{Q}$

SFOC

$T$

$t$

$\dot{V}$

w

W

W

$x$

$\varepsilon$

$\zeta_{\text {tot }} \quad$ Total exergetic efficiency

$\eta_{Q} \quad$ Heat recovery efficiency

$\eta_{R} \quad$ Rankine cycle efficiency

$\eta_{\text {tot }} \quad$ Total efficiency

Subscripts

0

av

crit Critical property

$f \quad$ Fuel Savings 


$\begin{array}{ll}H E x & \text { Heat exchanger } \\ H T & \text { High Temperature } \\ i & \text { Number of indicator } \\ i n & \text { Inlet } \\ j & \text { Group of indicators } \\ k & \text { Load of main engine } \\ L T & \text { Low Temperature } \\ \text { om } & \text { Operation and maintenance } \\ \text { ORC } & \text { Organic Rankine Cycle } \\ p & \text { Pump } \\ T & \text { Turbine }\end{array}$

\section{References}

[1] Tchanche B. F., Lambrinos G., Frangoudakis A., Papadakis G. (2011). Low-grade heat conversion into power using organic Rankine cycles - A review of various applications. Renewable \& Sustainable Energy Rev., 15, 3963-3979.

[2] Bonafin J., Pinamonti P., Reini M., Tremuli P. (2010). Performance Improving of an Internal Combustion Engine for Ship Propulsion with a Bottom ORC. ECOS 2010: Proceedings of the 23th International Conference on Efficiency, Cost, Optimization, Simulation, and Environmental Impact of Energy Systems, 2010 Jun 14-17, Lausanne, Switzerland. CreateSpace Independent Publishing Platform.

[3] Srinivasan K. K., Zdaniuk G. J., Chamra L. M., Midkiff K. C, Mago P. J. (2008). Improving the Efficiency of the Advanced Injection Low Pilot Ignited Natural Gas Engine Using Organic Rankine Cycles. J. Energy Resources Technol., 2, 1572-1579.

[4] Parimal P. S., Doyle E. F. (1976). Compounding the Truck Diesel Engine With an Organic Rankine Cycle System. SAE Technical Paper No:760343.

[5] Vaja I., Gambarotta A. (2008). Internal Combustion Engine (ICE) Bottoming with Organic Rankine Cycles (ORCs). Energy,35, 1084-1093.

[6] Geopeng Y., Gequn S., Hua T., Haiqiao W., Lina L. (2013). Simulation and thermodunamic analysis of a bottoming Organic Rankine Cycle (ORC) of Diesel engine (DE). Energy, 51, 281-290.

[7] Fubin Y., Xiaorui D., Hongguang Z., Zhen W., Kai Y., Jian Z., Enhua W., Hao L., Guangyao Z (2014). Performance analysis of waste heat recovery with a dual loop organic Rankine cycle (ORC) system for Diesel engine under various operating condition. Energy Conversion and Management, 80, 243 -255.

[8] Wang E. H., Zhang H. G., Fan B. Y., Ouyang M. G., Yang F. Y., Yang K., Wang Z., Zhang J., Yang F. B. (2014). Parametric analysis of a dual-loop ORC system for waste heat recovery of a diesel engine. Applied Thermal Eng., 67, 168 - 178.

[9] Yang K., Zhang H., Wang Z., Zhang J., Yang F., Wang E., Yao B. (2013). Study of zeotropic mixtures of ORC (organic Rankine Cycle) under engine various operating conditions. Energy, 58, 494-510.

[10] Zhang H. G., Wang E. H., Fan B. Y. (2013), A performance analysis of a novel system of a dual loop bottoming organic Rankine cycle (ORC) with a lightduty diesel engine. Applied Energy, 102, 1504 - 1513.
[11] Wang Z. Q., Zhou N. J., Guo J., Wang X. Y. (2012), Fluid selection and parametric optimization of organic Rankine cycle using low temperature waste heat. Energy, 40, 107 - 115.

[12] Krozer J., Mass K., Kothuis B. (2003), Demonstration of environmentally sound and cost-effective shipping, J. Cleaner Prod., 11, 767 - 777.

[13] Shu G., Liang Y., Wei H., Tian H., Zhao J., Liu L. (2013), A review of waste heat recovery on two-stroke IC engine aboard ships, Renewable \& Sustainable Energy Rev., 19, 385 - 401.

[14] Larsen U., Pierobon L., Haglind F., Gabrielii C. (2013), Design and optimisation of organic Rankine cycles for waste heat recovery in marine applications using the principles of natural selection. Energy, 55, $803-812$.

[15] Kalikatzarakis M. (2013), Exploitation of lowtemperature heat rejected from marine Diesel engines by Organic Rankine Cycle [diploma thesis]. Athens, Greece: National Technical University of Athens (in Greek).

[16] Bao J., Zhao L. (2013), A Review of Working Fluid and Expander Selections for Organic Rankine Cycle. Renewable \& Sustainable Energy Rev., 24, 325-342.

[17] MARPOL (1997), Revised MARPOL Annex VI, Regulation 12 - Ozone Depleting Substances.

[18] Linnhoff B., Townsend D. W., Boland D., Hewitt G. F., Thomas B. E. A., Guy A. R., Marsland R. H. (1982), A user guide on process integration for the efficient use of energy, The Institution of Chemical Engineers, Rugby, UK.

[19] Quoilin S., Declaye S., Tchanche B., Lemort V. (2011), Thermo-economic optimization of waste heat recovery using Organic Rankine Cycles. Applied Thermal Eng., 31, 2885-2893.

[20] Schuster A., Karellas S., Kakaras E., Spliethoff H. (2009), Energetic and economic investigation of Organic Rankine Cycle applications, Applied Thermal Eng., 29, 1809 - 1817.

[21] David G., Michel F., Sanchez L. (2011), Waste heat recovery projects using Organic Rankine Cycle technology - Examples of biogas engines and steel mills applications. World Engineers' Convention, Geneva, Switzerland.

[22] Afgan, N. H. Carvalho, M. G. (2000), Sustainable Assessment Method for Energy Systems: Indicators, Criteria and Decision Making Procedure. Kluwer Academic Publishers: Boston, USA.

[23] Frangopoulos C. A., Keramioti D. E. (2010), Multicriteria evaluation of energy systems with Sustainability Considerations. Entropy, 12, 10061020.

[24] Nikhil J. G., Lawankar S. M. (2012), Heat Transfer Analysis of Corrugated Plate Heat Exchanger of Different Plate Geometry: A Review. International J. Emerging Technology and Advanced Eng., 2, 2250 2459.

[25] Minea A. A., ed. (2012), Advances in industrial heat transfer. CRC Press, Boca Rotan. 